Article

\title{
Freshwater Ammonia-Oxidizing Archaea Retain amo $A$ mRNA and 16S rRNA during Ammonia Starvation
}

\author{
Elizabeth French and Annette Bollmann * \\ Department of Microbiology, Miami University, 32 Pearson Hall, 700 East High Street, \\ Oxford, OH 45056, USA; E-Mail: frenche2@miamioh.edu \\ * Author to whom correspondence should be addressed; E-Mail: bollmaa@miamioh.edu; \\ Tel.: +1-513-529-0426; Fax: +1-513-529-2431.
}

Academic Editors: Hans-Peter Klenk, Michael W. W. Adams and Roger A. Garrett

Received: 18 March 2015 / Accepted: 12 May 2015 / Published: 19 May 2015

\begin{abstract}
In their natural habitats, microorganisms are often exposed to periods of starvation if their substrates for energy generation or other nutrients are limiting. Many microorganisms have developed strategies to adapt to fluctuating nutrients and long-term starvation. In the environment, ammonia oxidizers have to compete with many different organisms for ammonium and are often exposed to long periods of ammonium starvation. We investigated the effect of ammonium starvation on ammonia-oxidizing archaea (AOA) and bacteria (AOB) enriched from freshwater lake sediments. Both AOA and AOB were able to recover even after almost two months of starvation; however, the recovery time differed. AOA and AOB retained their $16 \mathrm{~S}$ rRNA (ribosomes) throughout the complete starvation period. The AOA retained also a small portion of the mRNA of the ammonia monooxygenase subunit $\mathrm{A}$ $(a m o A)$ for the complete starvation period. However, after 10 days, no amoA mRNA was detected anymore in the AOB. These results indicate that AOA and AOB are able to survive longer periods of starvation, but might utilize different strategies.
\end{abstract}

Keywords: nitrification; ammonia oxidation; ammonia-oxidizing archaea; ammonia-oxidizing bacteria; starvation; ammonia monooxygenase 


\section{Introduction}

In natural systems, the majority of microorganisms exist in a physiological state similar to a stationary phase [1]. Nutrients become available in short pulses or are present in low concentrations. To survive these periods of starvation, microbes must be able to respond rapidly to fresh nutrients when they become available. Ammonium is one of the nutrients that is often limiting due to low nitrogen input and/or competition with other microorganisms.

Ammonia-oxidizing archaea and bacteria (AOA and AOB) are two groups of organisms that often encounter substrate starvation in the environment. Both AOB and AOA use the oxidation of ammonia to nitrite for the generation of energy. In AOB, this process is catalyzed by the enzymes ammonia monooxygenase (Amo) and hydroxylamine oxidoreductase (Hao) [2]. The first step of ammonia oxidation in AOA is also catalyzed by Amo; however, the subsequent steps of the reaction remain uncharacterized [3]. AOB exhibit strain-specific differences in their affinity for ammonia and the ability to compete for ammonia, but they share the ability to withstand extended periods of ammonia starvation [4-11]. The mechanism of ammonia starvation in AOB has not been fully elucidated; however, previous work demonstrated that $a m o A$ mRNA and 16S rRNA stability, as well as the stability of the Amo protein, during starvation may play a critical role in their survival and rapid recovery $[4,7,12]$. AOA have a higher affinity for ammonium than AOB $[13,14]$. Nitrosopumilus maritimus keeps a low number of amoA transcripts present in the cell during short-term starvation [15]. However, it is still unknown how quickly AOA recover from starvation and what happens to the ribosomes during starvation.

Here, we present experiments to monitor the starvation and recovery of the AOA enrichment culture AOA-AC1 and the AOB enrichment culture AOB-G5-7. We investigated the recovery time after starvation and the levels of amoA mRNA and 16S rRNA during starvation for a period up to almost two months.

\section{Results}

Both cultures (AOA-AC1 and AOB-G5-7) were inoculated in triplicate into mineral salts medium with $0.5 \mathrm{mM}$ ammonium. During growth, ammonium was converted to nitrite/nitrate (Figure S1). The specific growth rates were $0.017 \pm 0.0004 \mathrm{~h}^{-1}$ (AOA-AC1) and $0.057 \pm 0.018 \mathrm{~h}^{-1}$ (AOB-G5-7) before the cultures entered starvation. Starvation started when ammonium was no longer detectable in the cultures (Figure S1). Samples from the cultures at the end of the growth phase and during starvation were inoculated into fresh mineral salts medium with $0.5 \mathrm{mM}$ ammonium (recovery cultures); nitrite/nitrate was measured, and the specific growth rate and lag phase were determined (Figure S2).

The specific growth rates of the recovery cultures of AOA-AC1 did not differ significantly during the first ten days of starvation from those generated with late logarithmic/early stationary phase cultures. Recovery cultures inoculated with cultures that had been starved for 10 days or longer had a significantly longer lag phase than those inoculated with early stationary phase cultures. The specific growth rates of AOA-AC1 decreased after Day 10 of starvation, reaching a stable, lower value around Day 20 of starvation (Figure 1, Tables S1 and S2).

No significant differences were observed in the specific growth rate of any AOB-G5-7 recovery cultures, regardless of the length of the starvation period ( $0-50$ days; Figure 2, Table S1). 


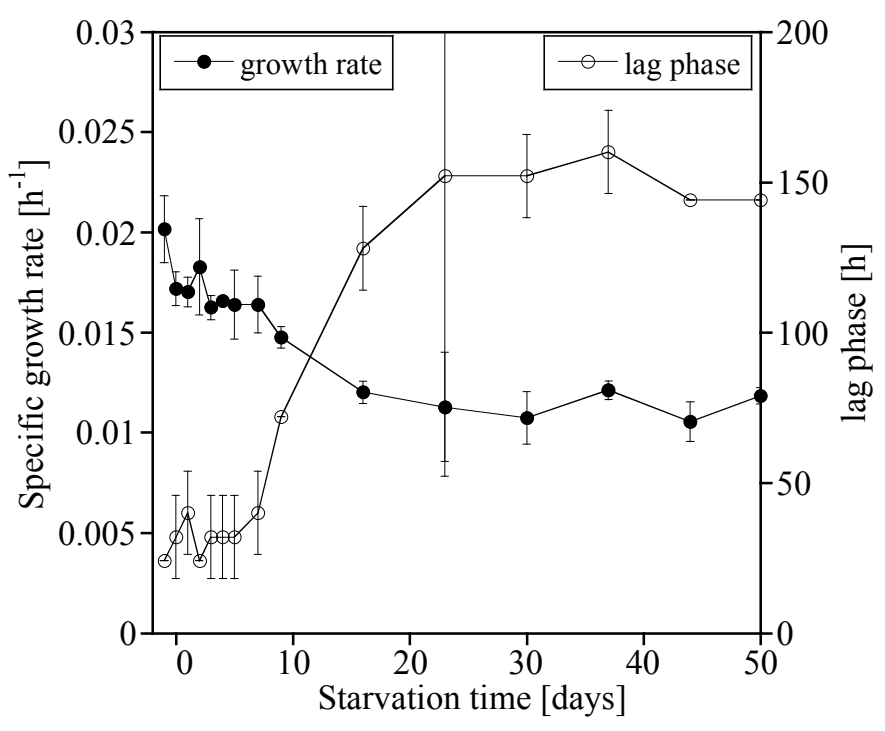

Figure 1. Specific growth rate $\left(\mathrm{h}^{-1}\right)$ and lag phase $(\mathrm{h})$ of the recovery cultures after starvation of the ammonia-oxidizing archaea (AOA) enrichment culture AOA-AC1 (mean $\pm \mathrm{SD}$, $n=3$ ). Starvation started at Day 0 .

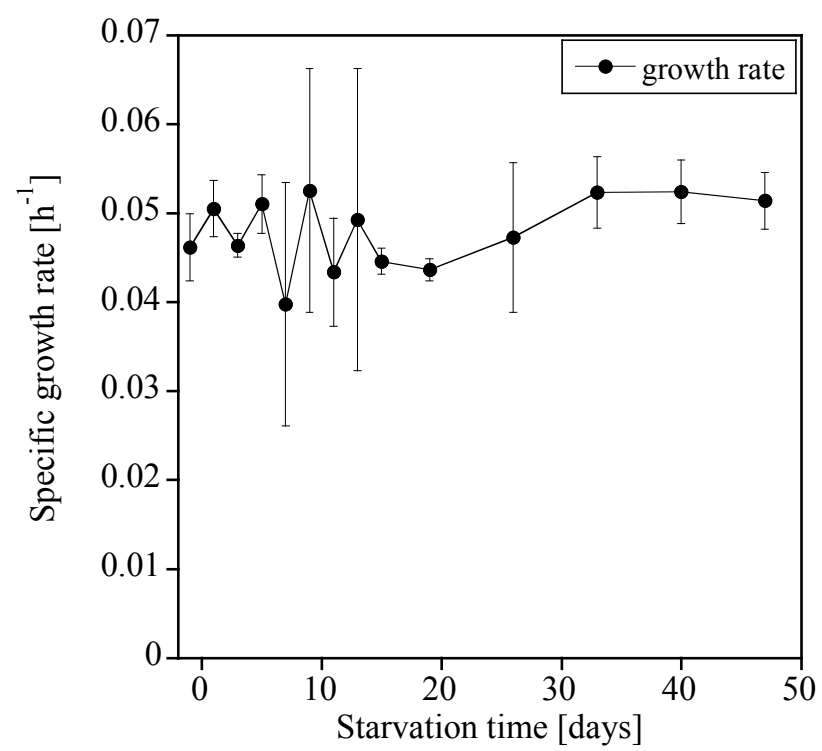

Figure 2. Specific growth rate $\left(\mathrm{h}^{-1}\right)$ of the recovery cultures after starvation of the ammonia-oxidizing bacteria (AOB) enrichment culture AOB-G5-7 (mean $\pm \mathrm{SD}, n=3$ ). Starvation started at Day 0. The lag phase of AOB-G5-7 was always $24 \mathrm{~h}$ or less, because the first sample from the recovery cultures was taken after $24 \mathrm{~h}$, and the culture was always active at that time.

RNA abundance (16S rRNA and amoA mRNA of AOA-AC1 and AOB-G5-7 and bacterial 16S rRNA of all bacteria in the cultures) was determined in selected samples over the course of the starvation period. The RNA concentration in the samples did not significantly change in the AOA-AC1 cultures, while it increased slightly in AOB-G5-7 (Table S3).

AOA-AC1 retained both amoA mRNA and 16S rRNA, while AOB-G5-7 only retained the 16S rRNA (Figures 3 and 4; Tables S4-S6). The amoA mRNA abundance decreased by two orders of magnitude 
in AOA-AC1 after 10 days of starvation and stayed constant around 1000-10,000 copies/ng RNA for the rest of the starvation period. The 16S rRNA abundance specific for AOA or AOB decreased slightly, but not significantly in the respective cultures. The bacterial 16S rRNA abundance decreased slightly in AOB-G5-7, but stayed constant in AOA-AC1.

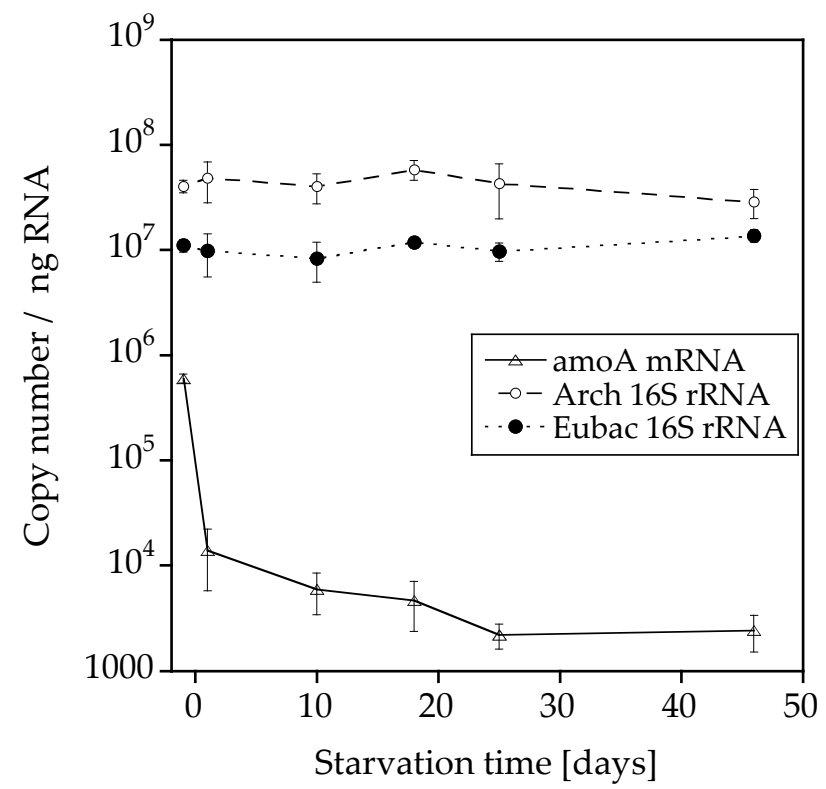

Figure 3. Archaeal amoA mRNA, AOA-specific $16 \mathrm{~S}$ rRNA and bacterial $16 \mathrm{~S}$ rRNA abundance (copies/ng RNA) during starvation of the AOA enrichment culture AC1 (mean $\pm \mathrm{SD}, n=3$ ).

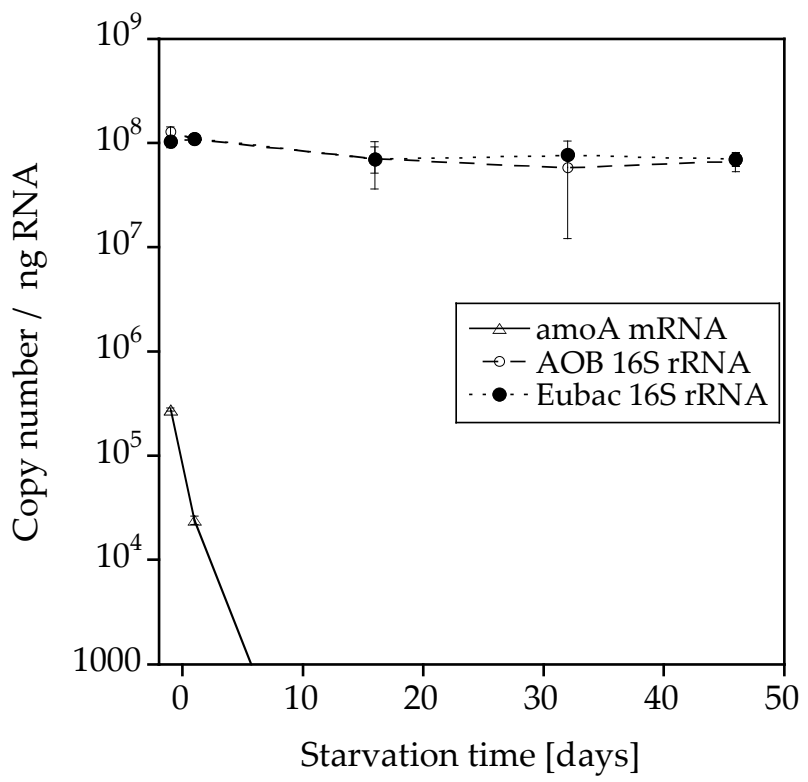

Figure 4. Bacterial amoA mRNA, AOB-specific $16 \mathrm{~S}$ rRNA and bacterial $16 \mathrm{~S}$ rRNA abundance (copies/ng RNA) during starvation of the AOB enrichment culture AOB-G5-7 (mean $\pm \mathrm{SD}, n=3$ ). 


\section{Discussion}

AOA-AC1 and AOB-G5-7 both recovered ammonia-oxidizing activity after up to 50 days of starvation; however, AOB-G5-7 recovered quicker than AOA-AC1 (Figures 1 and 2). Both cultures retained 16S rRNA (ribosomes) during the starvation period (Figures 3 and 4). Similar observations were made for other AOB, such as Nitrosospira briensis [4] and Nitrosomonas cryotolerans [6,7]. These results indicate that ribosome retention is very likely a shared adaptive strategy of AOA and AOB to survive nutrient starvation for long periods of time.

Interestingly, AOA-AC1 and AOB-G5-7 behaved differently with respect to amoA retention. The amo $A$ mRNA in the AOA cultures was detected during the complete starvation period, while amo $A$ mRNA in the AOB culture was only detected during the first few days. This difference could give insight into the differences in the starvation recovery strategies of AOA and AOB. During the initial starvation period, AOA-AC1 recovered quickly from starvation, but after 10 days, the recovery period increased. At the same time, the number of amoA mRNA copies decreased from $10^{6}$ to 1000 copies/ng RNA and stayed constant at that level for the rest of the starvation period. The ammonia oxidizing activity of starved Nitrosospira briensis recovered much slower after treatment of the cells with acetylene, an irreversible inhibitor of the ammonia monooxygenase, than in untreated cells, indicating that treated cells had to synthesize new protein, while untreated cells were able to directly oxidize ammonia with the existing Amo protein [4]. Immunoblot analysis showed long-term stability and an increase in abundance of the AmoB protein in Nitrosomonas eutropha during a one-year starvation period [12]. Therefore, the stability of the Amo protein complex is very likely to play an important role in the recovery of the AOB after starvation. AOA-AC1; however, it could have another mechanism, because the cells retain amo $\mathrm{A}$ mRNA for a longer period, and their recovery patterns show slowed down recovery. Unfortunately, we do not know anything about the protein stability in AOA and can therefore only speculate about the recovery mechanisms in AOA. Since the length of the recovery of the AOA increases over time, the Amo enzyme might be degraded and forcing the cells to synthesize new enzyme, while their mRNA might be constitutively expressed. Constitutive expression of genes involved in nitrogen metabolism has been observed in the oligotrophic marine microorganism Candidatus Pelagibacter ubique under nitrogen starvation [16]. To elucidate the mechanisms in more detail, future studies could compare mRNA and protein stability in short- and long-term starved AOA and AOB.

\section{Conclusions}

The cultures AOA-AC1 and AOB-G5-7 show differences in the retention of the amoA mRNA, as well as in the recovery of the ammonia-oxidizing activity. These differences indicate that the two microbes might use different strategies to survive longer periods of starvation.

\section{Material and Methods}

Cultures, AOB-G5-7: We used the AOB freshwater enrichment culture G5-7 that was enriched from Lake Drontermeer in the Netherlands (AOB-G5-7) as representative AOB culture. This culture contains the AOB Nitrosomonas sp. Is79, a close relative of Nitrosomonas oligotropha, with $97.8 \%$ identity on the 16S rRNA gene level, a nitrite oxidizer and co-cultivated heterotrophic bacteria and grows well at 
ammonium concentrations between $0.25 \mathrm{mM}$ and $5 \mathrm{mM}[10,17]$. AOA-AC1: The enrichment culture AOA-AC1 was enriched from the sediment of Lake Acton (Ohio) and contained an AOA that was 99\% identical based on the amo $A$ sequence and $99.7 \%$ based on the 16S rRNA gene sequence to the AOA in the enrichment culture AOA-DW belonging to the water column/sediment Group I.1a of the Thaumarchaeota $[18,19]$, a nitrite oxidizer and co-cultivated heterotrophic bacteria. The culture was around $80 \%$ enriched and contained no PCR-detectable AOB. Growth experiments showed that AOA-AC1 behaves similarly to the previously characterized AOA enrichment cultures AOA-DW, AOA-AC2 and AOA-AC5 [18,19]. AOA-AC1 grew at ammonium concentrations between $0.05 \mathrm{mM}$ and $1 \mathrm{mM}[19]$.

Medium: Mineral salts medium (MS medium) was used in all experiments containing $0.5 \mathrm{mM}$ ammonium as $\left(\mathrm{NH}_{4}{ }^{+}\right)_{2} \mathrm{SO}_{4}, 10 \mathrm{mM} \mathrm{NaCl}, 1 \mathrm{mM} \mathrm{KCl}, 1 \mathrm{mM} \mathrm{CaCl} 2 \cdot 2 \mathrm{H}_{2} \mathrm{O}, 0.2 \mathrm{mM} \mathrm{MgSO} \cdot 7 \mathrm{H}_{2} \mathrm{O}$, $1 \mathrm{~mL} \mathrm{~L}^{-1}$ trace elements solution and $2 \mathrm{mM}$ HEPES [20]. The $\mathrm{pH}$ was adjusted to 7.5 before autoclaving with $1 \mathrm{~N} \mathrm{NaOH}$. After autoclaving, separately-autoclaved $\mathrm{KH}_{2} \mathrm{PO}_{4}$ solution was added to obtain a final concentration of $0.4 \mathrm{mM}$ [20].

Starvation experiment: The enrichment cultures AOA-AC1 and AOB-G5-7 were inoculated in triplicate using $10 \% \mathrm{v} / \mathrm{v}$ into $1 \mathrm{~L}$ mineral salts medium with $0.5 \mathrm{mM}$ ammonium in 2-L Erlenmeyer flasks and incubated at $27{ }^{\circ} \mathrm{C}$ in the dark. The ammonium and nitrite/nitrate concentrations were measured on a daily basis to determine the onset of the starvation period. When the cultures had consumed approximately $80 \%$ of the initial ammonium concentration, they were assumed to be in the late logarithmic phase, and the first sample was removed for recovery experiments and molecular analysis. Once the ammonium in the 1-L cultures was completely consumed, the cultures were assumed to be starving. After this point, samples were collected for nitrite/nitrate and ammonium determination and recovery cultures every 24-48 hours for ten days and then once per week until the end of the experiment. Samples for molecular analysis were taken once per week.

Recovery cultures: Five $\mathrm{mL}$ of the cultures were inoculated into $45 \mathrm{~mL}$ of fresh mineral salts medium with $0.5 \mathrm{mM}$ ammonium in a $125-\mathrm{mL}$ Erlenmeyer flask to generate recovery cultures. The recovery cultures were incubated at $27^{\circ} \mathrm{C}$ in the dark and sampled on a daily basis to determine the nitrite/nitrate concentration. The specific growth rates were calculated from the linear increase of the log-transformed nitrite/nitrate concentrations over time, assuming that nitrite/nitrate production in the cultures is correlated with the growth of AOA and AOB [13,18,20,21].

Chemical analysis: Ammonium, nitrite and nitrate concentrations were determined in cell-free supernatants using colorimetric methods [20,22-24].

RNA isolation and conversion into cDNA (starvation experiment): Samples of the starved cultures were collected for molecular analysis by filtering $50 \mathrm{~mL}$ onto $0.1-\mu \mathrm{m}$ polycarbonate filters (AOA-AC1) and $0.22-\mu \mathrm{m}$ nitrocellulose filters (AOB-G5-7). RNA was isolated from the nitrocellulose filters using the Qiagen RNeasy RNA kit (Qiagen, Valencia, CA, USA) according to the manufacturer's recommendations with the following modifications. Acid-washed zirconium beads (1 g) (BioSpec Products, Bartlesville, OK, USA) and $1 \mathrm{~mL}$ buffer RTL were added to the filters. The filters were homogenized by bead beating for $30 \mathrm{~s}$ at $4800 \mathrm{rpm}$ and shaking the tubes on a titer plate shaker for 10 min at the highest speed. The RNA was eluted with $30 \mu \mathrm{L}$ RNase-free water. The RNA was treated with Ambion DNaseI (Life Technologies, Grand Island, NY, USA) for $60 \mathrm{~min}$ at $37^{\circ} \mathrm{C}$. RNA concentration and quality were measured by NanoDrop ${ }^{\mathrm{TM}} 3300$ Fluorospectrometer (Thermo Fisher Scientific, 
Wilmington, DE, USA). cDNA was synthesized using the Promega GoScript Reverse Transcriptase System (Promega) with random primers in $10 \mu \mathrm{L}$ volumes with $2 \mu \mathrm{L}$ samples.

Quantitative PCR (qPCR): The copy numbers of the 16S rRNA and amo $A$ transcripts (cDNA and RNA) were quantified using the Bioline SensiFAST SYBR NoROX Kit (Bioline USA, Taunton, MA, USA) in 5- $\mu \mathrm{L}$ reactions with $0.5 \mu \mathrm{L}$ sample in an Illumina Eco Real-Time PCR system (Illumina, San Diego, CA, USA) with the primers and conditions presented in Tables S7 and S8. Primers were designed with the NCBI-primer-BLAST tool or used as published (Table S7) [25,26]. All primers were tested for specificity to the respective DNA. Standard curves were constructed using plasmids containing the gene sequence of interest. The efficiency of the reactions ranged from $94 \%$ to $104 \%$ (Table S2). $\mathrm{R}^{2}$ was in all experiments $>0.99$. To determine the copy numbers in the RNA samples, qPCR was conducted using cDNA and RNA after DNase treatment as the template. RNA abundances were only taken into account if the copy numbers in the RNA samples were around the detection limit and at least $100 \times$ lower than the copy numbers in the cDNA samples.

\section{Acknowledgments}

This work was supported by the National Science Foundation Grant DEB-1120443 to Annette Bollmann. Elizabeth French was supported by the National Science Foundation Integrated Graduate Education and Research Training Grant DGE 0904560.

\section{Author Contributions}

Elizabeth French and Annette Bollmann conceived of, designed, performed and analyzed the experiments presented. Both authors wrote the paper and have read and approved the final manuscript.

\section{Supplementary Materials}

Supplementary materials can be accessed at: http://www.mdpi.com/2075-1729/5/2/1396/s1.

\section{Conflicts of Interest}

The authors declare no conflict of interest.

\section{References}

1. Kolter, R.; Siegele, D.A.; Tormo, A. The stationary phase of the bacterial life cycle. Annu. Rev. Microbiol. 1993, 47, 855-874.

2. Arp, D.; Sayavedra-Soto, L.; Hommes, N. Molecular biology and biochemistry of ammonia oxidation by Nitrosomonas europaea. Arch. Microbiol. 2002, 178, 250-255.

3. Walker, C.B.; de la Torre, J.R.; Klotz, M.G.; Urakawa, H.; Pinel, N.; Arp, D.J.; Brochier-Armanet, C.; Chain, P.S.G.; Chan, P.P.; Gollabgir, A.; et al. Nitrosopumilus maritimus genome reveals unique mechanisms for nitrification and autotrophy in globally distributed marine crenarchaea. Proc. Natl. Acad. Sci. USA 2010, 107, 8818-8823. 
4. Bollmann, A.; Schmidt, I.; Saunders, A.; Nicolaisen, M. Influence of starvation on potential ammonia-oxidizing activity and amoA mRNA levels of Nitrosospira briensis. Appl. Environ. Microbiol. 2005, 71, 1276-1282.

5. Bollmann, A.; Bar-Gilissen, M.; Laanbroek, H. Growth at low ammonium concentrations and starvation response as potential factors involved in niche differentiation among ammonia-oxidizing bacteria. Appl. Environ. Microbiol. 2002, 68, 4751-4757.

6. Johnstone, B.; Jones, R. Effects of light and $\mathrm{CO}$ on the survival of a marine ammonium-oxidizing bacterium during energy-source deprivation. Appl. Environ. Microbiol. 1988, 54, 2890-2893.

7. Johnstone, B.; Jones, R. Recovery of a marine chemolithotrophic ammonium-oxidizing bacterium from long-term energy-source deprivation. Can. J. Microbiol. 1988, 34, 1347-1350.

8. Jones, R.; Morita, R. Survival of a marine ammonium oxidizer under energy-source deprivation. Mar. Ecol. Prog. Ser. 1985, 26, 175-179.

9. Tappe, W.; Laverman, A.; Bohland, M.; Braster, M.; Rittershaus, S.; Groeneweg, J.; van Verseveld, H. Maintenance energy demand and starvation recovery dynamics of Nitrosomonas europaea and Nitrobacter winogradskyi cultivated in a retentostat with complete biomass retention. Appl. Environ. Microbiol. 1999, 65, 2471-2477.

10. Bollmann, A.; Laanbroek, H. Continuous culture enrichments of ammonia-oxidizing bacteria at low ammonium concentrations. FEMS Microbiol. Ecol. 2001, 37, 211-221.

11. Koops, H.; Pommerening-Roser, A. Distribution and ecophysiology of the nitrifying bacteria emphasizing cultured species. FEMS Microbiol. Ecol. 2001, 37, 1-9.

12. Pinck, C.; Coeur, C.; Potier, P.; Bock, E. Polyclonal antibodies recognizing the AmoB protein of ammonia oxidizers of the beta-subclass of the class Proteobacteria. Appl. Environ. Microbiol. 2001, 67, 118-124.

13. Könneke, M.; Bernhard, A.E.; de la Torré, J.R.; Walker, C.B.; Waterbury, J.B.; Stahl, D.A. Isolation of an autotrophic ammonia-oxidizing marine archaeon. Nature 2005, 437, 543-546.

14. Martens-Habbena, W.; Berube, P.M.; Urakawa, H.; de la Torré, J.R.; Stahl, D.A. Ammonia oxidation kinetics determine niche separation of nitrifying Archaea and Bacteria. Nature 2009, 461, 976-979.

15. Nakagawa, T.; Stahl, D.A. Transcriptional response of the archaeal ammonia oxidizer Nitrosopumilus maritimus to low and environmentally relevant ammonia concentrations. Appl. Environ. Microbiol. 2013, 79, 6911-6916.

16. Smith, D.P.; Thrash, J.C.; Nicora, C.D.; Lipton, M.S.; Burnum-Johnson, K.E.; Carini, P.; Smith, R.D.; Giovannoni, S.J. Proteomic and transcriptomic analyses of "Candidatus Pelagibacter ubique" describe the first PII-independent response to nitrogen limitation in a free-living Alphaproteobacterium. MBio 2013, 4, doi:10.1128/mBio.00133-12.

17. Bollmann, A.; Sedlacek, C.J.; Norton, J.; Laanbroek, H.J.; Suwa, Y.; Stein, L.Y.; Klotz, M.G.; Arp, D.; Sayavedra-Soto, L.; Lu, M.; et al. Complete genome sequence of Nitrosomonas sp. Is79, an ammonia oxidizing bacterium adapted to low ammonium concentrations. Stand. Genomic Sci. 2013, 7, 469-482.

18. French, E.; Kozlowski, J.A.; Mukherjee, M.; Bullerjahn, G.; Bollmann, A. Ecophysiological characterization of ammonia-oxidizing archaea and bacteria from freshwater. Appl. Environ. Microbiol. 2012, 78, 5773-5780. 
19. French, E.; Kozlowski, J.A.; Bollmann, A. Competition of Ammonia-oxidizing Archaea and Bacteria from freshwater environments. Manuscript under preparation.

20. Bollmann, A.; French, E.; Laanbroek, H.J. Isolation, cultivation, and characterization of ammonia-oxidizing bacteria and archaea adapted to low ammonium concentrations. Meth. Enzymol. 2011, 486, 55-88.

21. Belser, L.; Schmidt, E. Growth and oxidation-kinetics of three genera of ammonia-oxidizing nitrifiers. FEMS Microbiol. Lett. 1980, 7, 213-216.

22. Keeney, D.R.; Nelson, D.W. Nitrogen-Inorganic forms. In Methods in Soil Analysis-Part 2; Page, A.L., Ed.; American Society of Agronomy: Madison, WI, USA, 1982; pp. 643-698.

23. Kandeler, E.; Gerber, H. Short-Term Assay of Soil Urease Activity Using Colorimetric Determination of Ammonium. Biol. Fert. Soils 1988, 6, 68-72.

24. Shand, C.A.; Williams, B.L.; Coutts, G. Determination of N-species in soil extracts using microplate techniques. Talanta 2008, 74, 648-654.

25. Kowalchuk, G.; Stephen, J.; De Boer, W.; Prosser, J.; Embley, T.; Woldendorp, J. Analysis of ammonia-oxidizing bacteria of the beta subdivision of the class Proteobacteria in coastal sand dunes by denaturing gradient gel electrophoresis and sequencing of PCR-amplified 16S ribosomal DNA fragments. Appl. Environ. Microbiol. 1997, 63, 1489-1497.

26. Muyzer, G.; de Waal, E.C.; Uitterlinden, A.G. Profiling of complex microbial populations by denaturing gradient gel electrophoresis analysis of polymerase chain reaction-amplified genes coding for 16S rRNA. Appl. Environ. Microbiol. 1993, 59, 695-700.

(C) 2015 by the authors; licensee MDPI, Basel, Switzerland. This article is an open access article distributed under the terms and conditions of the Creative Commons Attribution license (http://creativecommons.org/licenses/by/4.0/). 